\title{
A GEOGRAFIA DA REORGANIZAÇÃO ESCOLAR: UMA ANÁLISE ESPACIAL A PARTIR DA CIDADE DE SÃO PAULO'
}

THE GEOGRAPHY OF SCHOOLS' REORGANIZATION:

A SPATIAL ANALYSIS FROM THE CITY OF SÃO PAULO

GEOGRAFÍA DE LA REORGANIZACIÓN DE LAS ESCUELAS:

UN ANÁLISIS DE ESPACIO DE LA CIUDAD DE SÃO PAULO

\author{
Eduardo Donizeti Girotto ${ }^{1}$ \\ Felipe Garcia Passos ${ }^{2}$ \\ Larissa de Campos $^{3}$ \\ João Victor Pavesi de Oliveira ${ }^{4}$
}

\begin{abstract}
RESUMO
Este artigo apresenta os resultados parciais do projeto A Reorganização Escolar em Mapas, desenvolvido no Laboratório de Ensino e Material Didático (LEMADI) do Departamento de Geografia da USP, com objetivo de demonstrar a importância da análise espacial na compreensão das políticas educacionais, representando espacialidades e correlacionando fenômenos, processos que são primordiais para sustentar os argumentos que fundamentam a tomada de decisão e a defesa de uma educação pública de qualidade para todos. Apresentamos a discussão a partir de mapas da cidade de São Paulo a fim de demonstrar os limites dos principais argumentos expostos pela Secretaria Estadual de Educação de São Paulo (SEE-SP) na defesa da proposta de reorganização escolar, bem como discutir se a revalorização do espaço urbano seria um dos objetivos não-explícitos dessa reorganização. Em nossas considerações sinalizamos que o argumento do decréscimo demográfico defendido pelo governo não se sustenta, uma vez que tal fenômeno não se converte automaticamente em diminuição de matrículas. Inferimos que a reorganização daria continuidade à municipalização da rede estadual, iniciada em 1995, e tem relação direta com o processo de revalorização do espaço, por haver correlação entre o fechamento de escolas, os lançamentos imobiliários e as grandes obras de infraestrutura de mobilidade.
\end{abstract}

PALAVRAS-CHAVE: Reorganização Escolar. Espaço Urbano. Cartografia.

\section{ABSTRACT}

This article presents the partial results from the project The Schools' Reorganization in Maps, developed in the Teaching and Courseware Lab (LEMADI) of the Geography Department of USP, with the objective of

\footnotetext{
${ }^{1}$ Doutor em Geografia Humana - Universidade de São Paulo (USP) - Professor - Departamento de Geografia Faculdade de Filosofia, Letras e Ciências Humanas da Universidade de São Paulo ( FFLCH/USP) - Cidade Universitária, São Paulo - SP. Email: egirotto@usp.br

${ }^{2}$ Mestrando em Geografia Humana - Faculdade de Educação da Universidade de São Paulo (FE/USP) - Cidade Universitária, São Paulo - SP. Email: felipepassos9@gmail.com

${ }^{3}$ Graduanda em Geografia - Faculdade de Filosofia, Letras e Ciências Humanas da Universidade de São Paulo (FFLCH/USP) - Cidade Universitária, São Paulo - SP. Email: larissadecampos2@gmail.com

${ }^{4}$ Professor de Geografia - Faculdade Drummond. Email: joao.pavesi@gmail.com
}

Submetido em: 30/11/2016 - Aceito em: 25/02/2017

(C) ETD- Educação Temática Digital Campinas, SP v.19 n.esp p. 134-158 jan./mar. 2017 
demonstrating the importance of a spatial analysis in the understanding of educational policies, representing spatialities and correlating phenomena, processes that are primordial to sustain the arguments that base decision making and the defense of quality public schooling for all. We present a discussion using maps from the city of São Paulo in order to demonstrate the limits of the main arguments presented by the Education Secretariat in the defense of the schools' reorganization proposal, as well as to discuss if the valorization of urban spaces is one of the non-explicit reasons for this reorganization. In our considerations we signalize that the demographic decline argument used by the government does not sustain itself, given that the there is not an automatic conversionto the number of enrolls. We have inferred that the reorganization gives continuity to the municipalization of state schools, which begun in 1995, and that it has direct relation with the process of spatial valorization, since there is a correlation between the closing schools, real estate launches and major mobility infrastructure works.

KEYWORDS: Schools' Reorganization.Urban Space.Cartography.

\section{RESUMEN}

Este artículo presenta los resultados parciales del proyecto "La reorganización escolar en mapas", desarrollado en el Laboratorio de Enseñanza y material didáctico del Departamento de Geografía de la Universidad de San Pablo, con objetivo de plantear la importancia de la análisis espacial en la comprensión de las políticas educacionales, representando espacialidades y correlacionando los fenómenos, procesos esenciales para sostener los argumentos que fundamentan las decisiones y la defensa de una educación pública de calidad para todos. Presentamos la discusión desde mapas de la ciudad de San Pablo para demonstrar los límites de los principales argumentos planteados por la Secretaria de la Educación, así como discutir si la revaluación del espacio urbano ha sido uno de los objetivos no-explícitos en la reorganización. En nuestras consideraciones, hemos verificado que el argumento dela reducción demográfica defendida por lo gobierno no se sustenta, una vez que ese fenómeno no se convierte automaticamente en caída de ingresos escolares. Inferimos que la reorganización resultaría en la continuidad de la municipalización de la red estadual, empezada en 1995, y tiene relación con el proceso de revaluación del espacio, una vez que existe correlación entre los cerramientos de escuelas, lanzamientos inmobiliarios y grandes obras de infraestructura y movilidad.

PALABRAS CLAVE: La reorganización escolar. Espacio Urbano. Cartografía.

\section{INTRODUÇÃO}

Em setembro de 2015, o governo estadual de São Paulo apresentou a proposta de Reorganização Escolar que, segundo site institucional, consistia na "disponibilização" (fechamento) de 94 unidades escolares por todo estado ( 25 delas localizadas na cidade de São Paulo) e reestruturação de outras $754^{5}$. Essa reorganização da rede teria como objetivo principal que cada unidade escolar atendesse um único ciclo da Educação Básica, focando-se em uma mesma faixa etária.

O argumento utilizado pela Secretaria Estadual de Educação de São Paulo (SEE-SP) para o fechamento das unidades de ensino se assenta em dois pontos principais: a mudança demográfica e o desempenho dos estudantes em avaliações externas. De acordo com a

\footnotetext{
${ }^{5}$ Cf.: http://www.educacao.sp.gov.br/reorganizacao/. Acessado em: dez. 2015.
}

C ETD-Educação Temática Digital Campinas, SP v.19 n.esp $\quad$ p. 134-158 jan./mar. 2017


Secretaria, entre 1998 e 2015, a rede estadual perdeu cerca de 2 milhões de alunos. Pela lógica do governo, essa redução da população em idade escolar teria produzido a presença de "salas de aulas ociosas".

Sobre o segundo ponto, temos em outro documento, também elaborado pela SEE$\mathrm{SP}$, que o rendimento das escolas de ciclo único no IDESP (Índice de Desenvolvimento da Educação do Estado de São Paulo) de 2014 foi 9,4\% acima da média geral, fato que justificaria a necessidade do remanejamento dos estudantes entre as unidades escolares, produzindo a transferência compulsória de 311 mil estudantes para escolas definidas pelo governo, sem que excedesse a distância de $1,5 \mathrm{~km}$ entre a residência do aluno e a nova unidade escolar ${ }^{6}$.

Após inúmeras críticas da comunidade escolar, de pesquisadores das diferentes universidades e de instituições da sociedade civil organizada e, principalmente, em decorrência da mobilização dos estudantes que iniciaram um amplo processo de ocupação de escolas contra o projeto de reorganização, o governo estadual foi obrigado a recuar, retirando o projeto. Desde então, inúmeras discussões têm sido feitas com o intuito de compreender as diferentes estratégias e intencionalidades que não foram explicitadas quando da apresentação da proposta de reorganização.

Neste sentido, apresentamos aqui resultados da pesquisa realizada no projeto $\mathbf{A}$ Reorganização Escolar em Mapas, desenvolvido no Laboratório de Ensino e Material Didático (LEMADI) do Departamento de Geografia da Universidade de São Paulo (USP). 0 seu principal objetivo é demonstrar a importância da análise espacial para a compreensão das políticas educacionais, entendendo que a localização, a distribuição e a correlação de fenômenos, assim como a busca por identificar espacialidades além do espaço físico, constituem processos primordiais para testar argumentos e hipóteses que fundamentam a tomada de decisões e a elaboração de projetos em defesa de uma educação pública equitativa e de qualidade para todos. Para tanto, apresentamos a discussão de mapas com o propósito de refletir sobre o raciocínio demográfico da SEE-SP e como estratégias de recomposição do espaço urbano não declaradas podem estar na base do projeto de reorganização escolar.

\footnotetext{
${ }^{6}$ Trata-se do documento "Escolas estaduais com uma única etapa de atendimento e seus reflexos no desempenho dos alunos", elaborado pela Coordenadoria de Informação, Monitoramento e Avaliação Educacional (CIMA), da SEE-SP, em 2015.
}

(C) ETD-Educação Temática Digital Campinas, SP v.19 n.esp $\quad$ p.134-158 jan./mar. 2017 
Sendo assim, o artigo organiza-se da seguinte forma: na primeira parte, retomamos as discussões sobre as reformas gerenciais da educação em São Paulo e no Brasil, tentando construir paralelos com a atual proposta, discutindo a centralidade que as políticas de avaliação têm assumido na indução destas reformas. Em seguida, apresentamos e discutimos os mapas produzidos em nosso projeto, problematizando argumentos trazidos pela SEE-SP como justificativa para a reorganização, analisando outros elementos que não são apresentados na proposta do governo estadual. Por fim, apontamos as perspectivas de continuidade de pesquisa, ressaltando a importância da representação cartográfica como meio de investigação sobre as políticas educacionais atuais, bem como a necessidade de se construir políticas articuladas que compreendam o direito à educação como um dos movimentos fundamentais para a construção do direito à cidade (LEFEBVRE, 2008) e para a justiça espacial (HARVEY, 2005).

Em um contexto no qual há tantas medidas que visam reduzir os gastos públicos em educação ${ }^{7}$, saúde e cultura, entre outras áreas, esperamos que este artigo possa contribuir na construção da luta em defesa de uma escola pública e de um projeto de sociedade para além da lógica do capital.

\section{A REORGANIZAÇÃO ESCOLAR E AS REFORMAS GERENCIAIS DA EDUCAÇÃO}

Para compreendermos a proposta de reorganização escolar apresentada pela SEE-SP em 2015, faz-se necessário localizá-la em um contexto mais amplo de transformações que têm afetado a educação pública, em suas diferentes etapas, nas últimas décadas. Trata-se de um movimento que tem buscado nortear a escola, o trabalho docente, a organização curricular e tantas outras dimensões da educação pública a partir de uma lógica empresarial e tecnicista.

É possível identificar a primeira etapa deste processo ainda na década de 1960, com a assinatura dos acordos entre o MEC e USAID durante o período militar brasileiro. Tais acordos, consolidados com a publicação da lei 5.692/71, transplantaram para o campo da educação uma série de conceitos e práticas vinculados ao mundo empresarial.

\footnotetext{
${ }^{7}$ Em especial, a Proposta de Emenda Constitucional 241 - 55 que estabelece um teto para os gastos públicos em todos os níveis federativos para os próximos 20 anos e a Medida Provisória 746 que propõe mudanças no Ensino Médio sem que haja uma ampla discussão sobre as condições financeiras e materiais de realização da proposta.
}

(C) ETD-Educação Temática Digital Campinas, SP v.19 n.esp $\quad$ p. 134-158 jan./mar. 2017 
Na década de 1990, sob o impacto do Consenso de Washington e de todo o ideário neoliberal, tivemos a realização de uma série de reformas administrativas do Estado brasileiro, iniciadas nos governos de Fernando Collor de Melo e Fernando Henrique Cardoso, com continuidades - apesar de algumas rupturas - nos governos de Luiz Inácio Lula da Silva e Dilma Rousseff. Tais reformas trouxeram impactos evidentes nas políticas educacionais, reforçando a lógica gerencial e tecnicista, e aplicando as metas estabelecidas na Conferência Mundial da Educação para Todos em Jomtien, Tailândia ${ }^{8}$. Vale destacar que tais políticas contaram com a efetiva participação das principais organizações internacionais - notadamente, Banco Mundial, Fundo Monetário Internacional, Organização para a Coordenação e Desenvolvimento Econômico e Organização Mundial do Comércio - em sua formulação e no processo de implementação em diferentes países. Os mecanismos de implementação são variados, mas passam, necessariamente, pela subordinação e dependência econômica dos países envolvidos às diretrizes desses órgãos que reorientam os gastos sociais.

Para fazer valer as suas concepções acerca do que é uma gestão eficaz da educação, a força dos organismos internacionais citados é ampliada com a participação, cada vez mais intensa, de grupos empresariais no debate sobre esta temática. Nos últimos anos, temos visto a criação de uma série de fundações - Instituto Ayrton Senna, Todos pela Educação, Fundação Lemann, Instituto Inspirare, Instituto Unibanco, Fundação Itaú, Instituto de Coresponsabilidade pela Educação, Instituto Natura - que passam a produzir materiais, campanhas publicitárias, cursos de formação inicial e continuada para professores, coordenadores e diretores de escola, fundamentados numa educação tecnicista, gerencial e neoliberal. Para essas fundações, a resolução das principais questões acerca da educação pública no país passa pela incorporação de mecanismos de administração adotados no mundo empresarial, tornando-se cada vez mais comum falar de metas, eficiências, produtividade na educação pública brasileira.

Portanto, entender o processo que resultou na proposta de reorganização escolar apresentado pela SEE-SP em 2015 pressupõe a compreensão do lugar de destaque que tem ocupado esta lógica gerencial e sua influência sobre as políticas educacionais brasileiras.

\footnotetext{
${ }^{8}$ Neste evento, ocorrido um ano após a reunião do Consenso de Washington, foram definidas metas para os dez anos seguintes, para todos os países que assinaram a declaração, dentre eles o Brasil: erradicação do analfabetismo; universalização da educação fundamental; eliminação da evasão e a repetência escolar; descentralização administrativa e financeira; divisão da responsabilidade entre o Estado e a sociedade, através de parcerias com empresas, comunidades e a municipalização do ensino fundamental; avaliação do desempenho do(a) professor(a) e institucional; desenvolvimento do ensino à distância e reestruturação da carreira docente.
}

(C) ETD-Educação Temática Digital Campinas, SP v.19 n.esp $\quad$ p. 134-158 jan./mar. 2017 
Entre outras medidas, gostaríamos de destacar as implantações de avaliações com forte caráter de responsabilização do docente como instrumento que melhor representa a continuidade de princípios neoliberais em governos com plataformas políticas distintas.

Em diferentes países que têm adotado políticas de avaliação sob a lógica neoliberal, o modelo é bastante semelhante. Essa concepção tem sido utilizada como um mecanismo de controle, cada vez mais aprimorado, com o intuito de incentivar e coibir certas práticas educativas de alunos e professores. Tal domínio se dá pela centralidade que as políticas de avaliação têm assumido no conjunto das políticas educacionais, sendo um dos pilares para o desenvolvimento das mesmas. Quase todas as mudanças que têm sido feitas na educação carreira docente, currículo, organização do tempo de aula etc. - são justificadas a partir dos resultados das avaliações centralizadas. No entanto, para que este monitoramento possa acontecer de maneira cada vez mais intensa, é preciso simplificar o processo de avaliação, fundamentalmente complexo, colocando, em seu lugar, um formato padronizado de testes sobre alguns conteúdos eleitos como essenciais. Na maioria dos casos, tais conteúdos são o domínio da língua materna e o da matemática escolar.

Reduzida a sua complexidade, os dados das avaliações podem ser tabulados, tornando-se estatísticas que passam a definir novas reformas gerenciais da educação. Tratase de um efeito em cascata: a avaliação que deveria ser um processo que levasse em conta as múltiplas variáveis do processo educativo, nos modelos aplicados, passa a contribuir para que os agentes da reforma distorçam a realidade educativa. Com esta distorção é possível criar um processo de responsabilização dos professores, que se tornamos principais alvos das reformas gerenciais, sendo atacados em seus direitos básicos, como nas condições de carreira e de trabalho.

O incentivo à criação de políticas educacionais que atrelem, diretamente, os resultados das avaliações padronizadas não apenas à remuneração dos professores, mas também com a continuidade dos mesmos na profissão, é conservado por autores como Kane et al. (2006). Defendendo uma política de carreira a qual denomina de "para cima ou para fora", os autores apontam que os professores que não conseguirem bom desempenho na carreira - entendido aqui como melhorar os resultados dos alunos em avaliações padronizadas - deverão sofrer sanções que podem, inclusive, resultar na demissão. Nesta lógica, o professor é entendido como o único responsável no processo de ensino e aprendizagem.

Concepção semelhante é apresentada por Neubauer \& Silveira (2008). Ao analisar as políticas de gestão educacional em diferentes países da América Latina, as autoras tecem elogios à experiência da Nicarágua, que, entre outras coisas, implementou um "banco de

(C) ETD-Educação Temática Digital Campinas, SP v.19 n.esp $\quad$ p.134-158 jan./mar. 2017 
pais". Trata-se de uma lista de pais que se voluntariam para substituir professores quando os mesmos faltam. Além disso, os pais das escolas da Nicarágua que adotaram este novo modelo de gestão tinham poder para demitir professores que consideravam ineficientes. Ao analisar estas experiências, as autoras defendem:

1. criar uma política de pessoal diferenciada com sanções e estímulos significativos (bonificações, financiamento habitacional especial, pontuação diferencial para efeitos de aposentadoria, etc.) que estimule, inclusive, os professores e diretores mais capacitados a se manterem nas escolas, principalmente nas que recebem as crianças mais pobres assim como aquelas com as maiores dificuldades de aprendizagem;

2. estabelecer critérios claros e efetivos de premiação para as escolas que apresentem os melhores ganhos agregados num determinado período de tempo, o que certamente as incentivará a inovar suas práticas pedagógicas e a se comprometer com a melhoria da aprendizagem dos alunos;

3. utilizar os resultados da avaliação das escolas para orientar as tomadas de decisão em políticas públicas, principalmente no que se refere aos programas de apoio e formação continuada do magistério em função dos problemas de rendimento escolar identificados, priorizando as escolas com as avaliações mais negativas. (NEUBAUER \& SILVEIRA, 2008, p. 28-29).

Nas recomendações feitas pelas autoras, estão presentes os conceitos norteadores dessa política de avaliação com vistas à responsabilização docente. Termos como premiação, sanção, bonificação são cada vez mais presentes no ideário educacional, com efetiva capacidade de controle sobre o trabalho docente e o processo de ensino e aprendizagem.

É interessante notar que, apesar da terceira recomendação indicar que os resultados das avaliações devem ser utilizados para a criação de programas de melhoria da qualidade das escolas que obtiveram desempenho inferior ao esperado, o que temos visto é uma ação exatamente contrária. As escolas com baixo desempenho têm sido sistematicamente responsabilizadas pelo mesmo, sofrendo sanções que vão desde a diminuição de recursos ao fechamento, como podemos verificar na atual proposta de reorganização escolar.

Em texto publicado em 2000, Maria Helena Guimarães de Castroaponta o lugar das avaliações nas políticas educacionais brasileiras ${ }^{9}$. Segundo a autora,

\footnotetext{
${ }^{9}$ Foi Secretária Estadual de Educação de São Paulo durante da gestão de José Serra (2006-2010) do PSDB e responsável pela implementação do currículo único e pela avaliação por mérito dos professores da rede estadual. Em 2016, ocupa o cargo de Secretária Executiva do Ministério da Educação.
}

(C) ETD-Educação Temática Digital Campinas, SP v.19 n.esp $\quad$ p. 134-158 jan./mar. 2017 
Na década de 90, especialmente nos últimos quatro anos, a avaliação educacional assumiu um lugar de grande destaque na agenda das políticas públicas de educação no Brasil, acompanhando uma tendência que já vinha sendo seguida por diferentes países desde os anos 70. Hoje, existe sólido e elevado grau de consenso entre os gestores, educadores e especialistas sobre a relevância dos sistemas de avaliação para orientar as reformas educacionais e, sobretudo, para induzir políticas de melhoria da qualidade do ensino. Por essa razão, tem havido uma preocupação cada vez maior em aperfeiçoar os mecanismos de monitoramento do desempenho dos sistemas de ensino, com foco centrado na aprendizagem dos alunos e nos diferentes fatores associados ao rendimento escolar. (CASTRO, 2000, p. 27).

No trecho, evidencia-se a centralidade que os sistemas de avaliação assumem na indução de políticas que visam alterar as práticas educativas em diferentes unidades escolares, afetando profundamente a autonomia da escola, dos professores e dos alunos. Trata-se, portanto, de um processo no qual os sistemas de avaliação se tornam aquilo que Sass \& Minhoto (2010, p.1) denominam de avaliação como uma tecnologia, "isto é, conhecimento científico aplicado para promover o ajustamento e a adaptação dos indivíduos e das escolas às exigências do sistema social”.

Neste sentido, a lógica de controle e responsabilização pode ser entendida como um dos elementos norteadores das políticas educacionais do governo estadual de São Paulo desde 1995. Algumas medidas fazem parte deste contexto: criação do Sistema de Avaliação do Rendimento Escolar do Estado de São Paulo (SARESP) em 1996, implantação da política de bônus por mérito atrelada ao desempenho dos estudantes nas avaliações padronizadas em 2000 e elaboração de um currículo centralizado e único em 2008. No caso da reorganização escolar, novamente os dados das avaliações padronizadas foram utilizados, como mencionado para subsidiar a decisão da SEE-SP de fechar 94 escolas e transferir mais de 300 mil alunos. No trecho a seguir, fica explícita a relação entre os resultados das avaliações padronizadas e a proposta da reorganização escolar:

\footnotetext{
Nesse sentido, esse relatório visa elucidar que os dados do IDESP (indicador que combina os resultados do SARESP - Sistema de Avaliação de Rendimento Escolar do Estado de São Paulo - com informações sobre a taxa média de aprovação em cada etapa da escolarização), para o ano de 2014, confirmam que, tanto no Ensino Fundamental Anos Iniciais e Anos Finais, como no Ensino Médio, as escolas que oferecem exclusivamente apenas uma das etapas do ensino, apresentaram resultados mais satisfatórios. (PANTOJO et al., 2015, p.3).
}

É interessante perceber que os autores do relatório se utilizam dos resultados de apenas um ano (2014) para alcançarem a conclusão de que o desempenho dos estudantes é maior em escolas com ciclo único. Nesta conclusão está evidente uma lógica que busca tomar como simples um processo que é fundamentalmente complexo e que pode produzir efeitos de agravamento da problemática. É importante ressaltar que este argumento não se

C ETD-Educação Temática Digital Campinas, SP v.19 n.esp $\quad$ p. 134-158 jan./mar. 2017 
configura como uma novidade, uma vez que foi utilizado no primeiro processo de reorganização escolar feito a partir de 1995 e analisado por Adrião (2008). Naquele momento, a secretaria estadual de educação tinha como principal objetivo acabar com as escolas de oito anos, criando uma escola para estudantes entre 7 e 10 anos e outra para estudantes entre 11 e 14 anos. A justificativa é muito semelhante àquela apresentada no documento que defende a atual reorganização: os alunos teriam um melhor desempenho na aprendizagem nesta nova organização escolar. $O$ fracasso desta primeira reorganização, medido pelos próprios índices oficiais do governo do estado, já pode, em certa medida, indicar os limites desta concepção.

A partir desta discussão é possível compreender o lugar da proposta de reorganização nesse contexto de reforma gerencial da educação em São Paulo e no Brasil. Neste processo é perceptívelque o intuito do modelo de avaliação que tem orientado as políticas públicas nos últimos 20 anos em São Paulo, e em grande parte do país, não é melhorar a qualidade da educação pública, seja no acesso, na permanência ou nas condições de apropriação e produção de conhecimentos. Se de fato fosse este o objetivo, a lógica e o formato da avaliação precisariam mudar, pois o modelo atual só contribui para ampliar a distorção daquilo que de fato acontece na escola, uma vez que, como vimos, toma como unidimensional um fenômeno estruturalmente complexo. Ao contrário, o que a história recente tem apontado, e que a proposta de reorganização escolar vem apenas comprovar, é que o atual mecanismo de avaliação tem cumprido papel central nas reformas neoliberais da educação em todo o mundo e por isso é fundamental denunciá-lo e combatêlo.

Outro elemento importante para aprofundar a discussão se refere à compreensão de que a postura atual de construção das políticas educacionais acontece sem um amplo debate com a sociedade e sem um diagnóstico qualitativo e multidisciplinar das problemáticas que se visa combater. Essa postura da SEE-SP não se iniciou atualmente. Ao recuperarmos o documento "Mudar para melhorar: uma escola para a criança e outra para adolescentes" elaborado pela da SEE-SP em 1995, que apresenta e justifica a primeira proposta de reorganização escolar, encontraremos uma proposta de intervenção na rede estadual semelhante à apresentada pelo governo estadual em 2015.

Tal documento foi apresentado à sociedade em novembro de 1995 e em suas páginas iniciais afirma que "a reorganização que ora se inicia é um processo que envolve pessoas, carreiras, projetos de vida e vai afetar tanto o universo escolar, como a população em geral. Assim, sua implantação será gradual, sem atropelos" (SEE-SP, 1995, p. 8). No entanto, o mesmo documento notifica que haverá pouco tempo para discussão, uma vez que, como aponta o texto, "a partir do próximo ano [1996], estudantes de Ciclo Básico a 4ạ

(C) ETD-Educação Temática Digital Campinas, SP v.19 n.esp $\quad$ p. 134-158 jan./mar. 2017 
série irão estudar em prédios escolares diferentes dos de seus colegas de $5 \underline{a}$ série em diante. Crianças de um lado, adolescentes e jovens de outro" (SEE-SP, 1995, p. 7). No limite, toda a comunidade escolar teve um prazo de pouco mais de 4 meses para se adaptar às mudanças preconizadas pela SEE-SP, sem que as mesmas fossem discutidas, analisadas, reconstruídas e, até mesmo, refutadas.

Outra afinidade do texto de 1995 em relação ao atual documento diz respeito à utilização de situações isoladas de escolas, tanto públicas como privadas, para demonstrar a viabilidade da reorganização sem que um amplo processo de acompanhamento e discussão fosse realizado.

\begin{abstract}
Escolas que dão certo, que conseguem fazer com que seus alunos aprendam, raramente misturam, num mesmo prédio, alunos de faixas etárias diferentes. É o caso de algumas das instituições de ensino particular mais conceituadas do Estado, em que as classes de pré-escola, Ciclo Básico a 4ạ série, 5a a 8a e 2o grau funcionam em espaços diferentes. Dentre as escolas públicas que já adotam este modelo, destaca-se a conhecida "Experimental da Lapa", que oferece desde o préprimário até o Centro Especial de Formação e Aperfeiçoamento do Magistério CEFAM. Cada um destes segmentos ocupa um espaço distinto, com entradas e saídas independentes. $O$ sucesso deste tipo de organização reflete-se no fato de que os índices de reprovação não ultrapassam $15 \%$ e, praticamente, não existe evasão. (SEE-SP, 1995, p. 22-23).
\end{abstract}

Novamente, desvirtua-se a realidade multifacetada da educação, autonomizando um dos elementos que a constitui, colocando como causa única a divisão da escola por ciclos. Desconsidera-se, nesta análise, inúmeros outros elementos que, em conjunto e relação, contribuem para o entendimento daquilo que acontece na escola - perfil e quantidade de alunos e professores, condições de trabalho, acesso e uso dos materiais didáticos, formação inicial e continuada dos professores, ambiente da escola, participação dos pais e de toda a comunidade etc. No entanto, tal documento não busca se fundamentar no interior de uma discussão séria sobre a escola e a educação pública. Sua sintaxe se assemelha, assim como a do documento de 2015, a uma peça de propaganda que, por meio de raciocínios simplificadores, objetiva ocultar as profundas problemáticas presentes na proposta de reorganização. Como peça de propaganda, a proposta difunde a ideia de que não há perdedores neste processo, como fica explícito no trecho a seguir retirado da contracapa do projeto:

A reorganização das escolas irá melhorar a qualidade de ensino e o aproveitamento dos alunos. As condições de trabalho e os salários dos professores também vão melhorar. E o melhor de tudo é que isto vai garantir, para todos os alunos, aprendizagem e progresso durante os oito anos de escola obrigatória. (SEESP, 1995, p.1)

(C) ETD-Educação Temática Digital Campinas, SP v.19 n.esp $\quad$ p.134-158 jan./mar. 2017 
Há, porém, no documento de 1995, um discurso mais consolidado em torno do objetivo de racionalizar os recursos da secretaria estadual de educação, seja pela menor necessidade de contratação de professores, da não sobreposição de ambientes educacionais, seja pela junção de classes. No entanto, este projeto de racionalização se apresenta contraditório com as promessas feitas no documento com a evidente intenção de conquistar a adesão de professores, funcionários e alunos.

Aos professores, promete-se uma melhor condição de trabalho, com ampliação da remuneração, pois "a reorganização irá assegurar condições adequadas ao trabalho docente. Para melhorar a qualidade do ensino é indispensável valorizar o professor" (SEESP, 1995, p. 26). Além disso, segundo o documento, será o fim do deslocamento do professor por diferentes unidades escolares, uma vez que este é um problema que a reorganização pretende combater:

Hoje, há inúmeras escolas pequenas, com poucas salas e, portanto, com um número reduzido de classes de $5 \underline{a}$ a $8^{a}$ série e segundo grau. Assim, muitos professores precisam deslocar-se por até quatro escolas, para conseguirem completar sua carga horária. Deste jeito, como desenvolver um trabalho pedagógico consistente e coletivo? (SEE-SP, 1995, p.21).

Aos estudantes, é prometida uma mudança dos espaços da escola, uma vez que "a reorganização criará espaços físicos adequados às necessidades das diferentes faixas etárias. Crianças e jovens diferem nos aspectos físicos, sociais e psicológicos e precisam que isto seja levado em conta" (SEE-SP, 1995, p. 25). Vejamos o que diz o documento sobre as

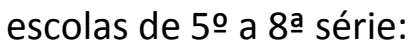

A escola de 5a série em diante implementará laboratórios e salas-ambiente. Investirá em computadores, oficinas, bibliotecas e quadras poliesportivas. Haverá mais espaço para o Grêmio Estudantil funcionar. Será mais fácil organizar festivais de música e teatro, fanfarras, jornadas esportivas e outras atividades de enriquecimento curricular, que interessam especialmente a adolescentes e jovens adultos. Nesta escola serão realizadas parcerias com o objetivo de desenvolver habilidades profissionais dos alunos, preparando-os para enfrentar um mercado de trabalho flexível, em permanente mutação. (SEE-SP, 1995, p. 26).

Esta contradição se materializa nos dados atuais do Censo Escolar da Rede Estadual de São Paulo. Segundo os dados de 2014, apenas 34,7\% das escolas sob a administração da SEE-SP possuem laboratório de ciências (e aqui não é possível saber se, de fato, os mesmos são utilizados no processo educativo por alunos e professores), $19 \%$ possuem sala de

(C) ETD-Educação Temática Digital Campinas, SP v.19 n.esp $\quad$ p.134-158 jan./mar. 2017 
recursos para a Educação Especial; e ainda existem 15\% de escolas sem bibliotecas ${ }^{10}$ e $10 \%$ sem quadras poliesportivas. Apesar de ser elevado o número de escolas com salas de informática $(95,8 \%)$, a proporção aluno/computador é inadequada $(16,7$ alunos para cada computador). Diante destes números, é possível concluir que a lógica de racionalização dos recursos se sobrepôs às promessas feitas aos alunos.

Por fim, aos coordenadores e diretores promete-se um ambiente escolar onde seja possível não apenas manter as aparências, como aponta o documento:

Mas, como conseguir isso, se não é possível reunir os docentes (veja o item anterior) e se a escola é uma confusão de sinais para entradas e saídas de alunos e professores, onde parece que o fundamental é apenas manter uma aparência mínima de disciplina e evitar a instauração de um completo caos? (SEE-SP, 1995, p. 21).

É fundamental observar que os problemas relatados no documento de 1995 e que justificariam a necessidade daquela primeira reorganização continuam latentes na rede estadual de educação de São Paulo, sendo citados, inclusive, no documento que justifica a atual proposta, indicando os limites de políticas educacionais que apresentam soluções simplistas para problemas complexos.

Observando o impacto da reorganização dos anos 1990 na política de fechamento de escolas, encontramos somente informações pouco precisas. Em reportagem da época, a assessoria da SEE-SP afirmou terem sido 148 unidades escolares fechadas por todo estado ${ }^{11}$. Já em levantamento realizado por Adrião (2006, p. 141), compreendendo fechamentos de escolas e unidades transferidas para os municípios no processo de municipalização, o número chega a 864 escolas - em 1995 eram 6.783 unidades escolares estaduais e em 1998 eram 5.919. Especificamente para o município de São Paulo, conforme levantamento feito por França (2008), foram 20 escolas fechadas para o ano de 1996. Ao verificarmos a destinação dos imóveis, podemos reconhecer outras dimensões da política de reorganização escolar:

\footnotetext{
${ }^{10}$ É importante destacar que a Resolução SE no 70 de 21 de outubro de 2011 transformou as bibliotecas escolares em salas de leitura, com professores da rede assumindo a responsabilidade por este equipamento escolar, substituindo a contratação de bibliotecários. Resolução disponível em:

http://siau.edunet.sp.gov.br/ItemLise/arquivos/2 16.HTM?Time=24/02/2017\%2018:06:14. Acessado em: fev. 2017.

11 Jornal Folha de S. Paulo, 02 de ago de 1997. Primeiro Caderno, p. 10.
}

(C) ETD-Educação Temática Digital Campinas, SP v.19 n.esp $\quad$ p.134-158 jan./mar. 2017 
Algumas delas [unidades escolares] foram reutilizadas para fins pedagógicos; outras para atividades administrativas da SEE, como diretorias de ensino; outras foram reutilizadas em órgãos de outras secretarias do estado, como unidades da polícia militar; e algumas foram vendidas. É o caso da extinta EE Prof. José Alves de Camargo Vila Mafra, na Vila Formosa, onde foi construído um condomínio fechado. (FRANCA, 2008, p. 80).

Neste sentido, torna-se fundamental aproximar o debate ao contexto espacial das unidades escolares ameaçadas de fechamento, buscando compreender de que maneira elas podem participar de estratégias de reorganização espacial da cidade. Inicialmente, faremos esse movimento testando a justificativa demográfica apresentada pela SEE-SP e, em seguida, investigando outros possíveis processos, agentes e interesses velados no discurso de busca da qualidade educacional.

\section{DO ARGUMENTO DEMOGRÁFICO AOS SUJEITOS - NÃO TÃO - OCULTOS DA REORGANIZAÇÃO}

No documento "Escolas estaduais com uma única etapa de atendimento e seus reflexos no desempenho dos alunos"a SEE-SP (2015) apresenta as justificativas para a realização da reorganização escolar. Um dos aspectos aludidos pelos técnicos diz respeito à mudança do perfil demográfico da população de São Paulo. De acordo com o texto, o decréscimo da população em idade escolar resultaria em uma diminuição do número de matrículas nas escolas estaduais de São Paulo, gerando aquilo que o documento denomina de salas ociosas. Segundo a secretaria, seria necessário fechar algumas das unidades escolares para haver um ajustamento na relação entre a oferta de escola e a demanda por ela.

Diante da proposta da SEE-SP, faremos dois movimentos de investigação: primeiramente, analisaremos o argumento demográfico e a sua relação com a variação de matrículas e, em seguida, buscaremos correspondência do projeto de reorganização com os processos de municipalização escolar e de valorização do espaço urbano. Em relação ao cenário demográfico, nos aproximando de sua situação atual, apresentamos dois mapas com a variação da população em idade escolar. No mapa 1 , com dados do IBGE, a variação anual entre 2000 e 2010 aponta decréscimo bem distribuído pelo município. Já no mapa 2, os dados de projeção da Seade entre 2015 e 2016 apresentam uma variação que passa de positiva para negativa no sentido centro-periferia, contrastando com o mapa anterior em relação à geografia do fenômeno e também por apresentar um equilíbrio no total do município. No portal de divulgação dos dados, a Seade não disponibiliza notas sobre quais

(C) ETD-Educação Temática Digital Campinas, SP v.19 n.esp $\quad$ p.134-158 jan./mar. 2017 
são as variáveis que compõem a sua projeção demográfica, o que não auxilia a reflexão sobre a diferença entre os dados constatada nos mapas.

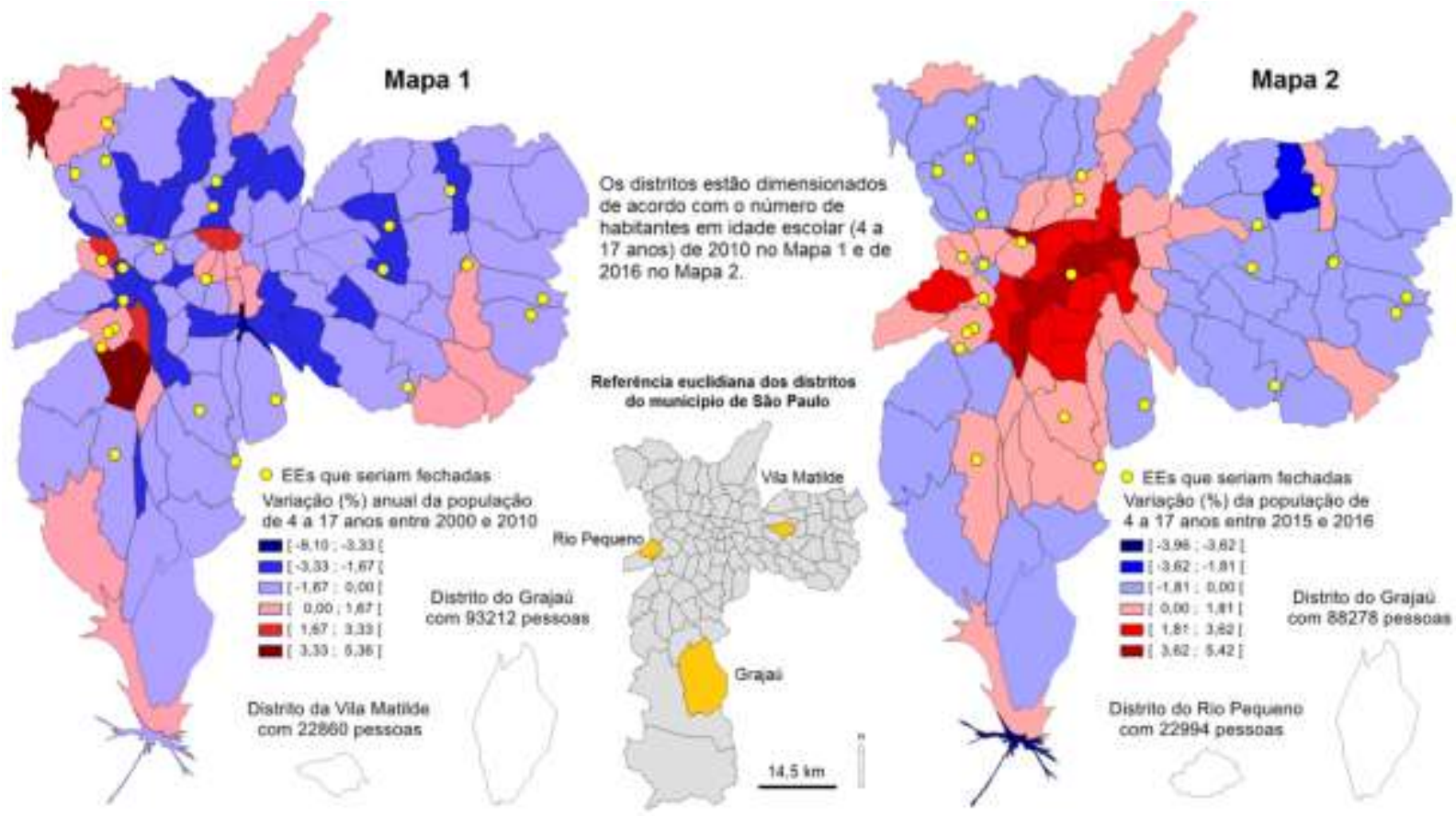

Figura 112 Comparativo demográfico. Mapa 1: EEs ameaçadas sobre a variação da população em idade escolar entre 2000 e 2010; Mapa 2 - EEs ameaçadas sobre a variação da população em idade escolar entre 2015 e 2016.

Fonte: dados demográficos, IBGE e Seade respectivamente. Softwares de elaboração: anamorfose: Scape Toad; discretização: Cartes \& Données. Método estatístico: padrão centrado no zero.

Nos mapas 1 e 2, ao olharmos para a localização das EEs que seriam fechadas em 2016, notamos a falta de correspondência entre elas e o decréscimo demográfico apontado que justificaria a intervenção pretendida. As $25 \mathrm{EEs}$ encontram-se tanto em áreas próximas ao centro quanto em regiões periféricas, tendo os distritos índice de crescimento negativo ou positivo. Ao mesmo tempo em que apresenta seu argumento demográfico, a SEE-SP não faz menção a uma questão fundamental para a análise da demanda de cada unidade escolar: de onde vêm os alunos? A busca pela resposta a esta pergunta nos indica,

\footnotetext{
12 No primeiro mapa o tamanho dos distritos foi dimensionado com a população em idade escolar de 2010 e nos mapas 2, 3 e 4 com a mesma faixa etária, mas com dados de 2016. A opção por essa métrica encontra pertinência por termos em análise fenômenos (variação da população, do número de matrícula e da quantidade de classes) cuja natureza é social e, portanto, pouco relativizada pela área física do território dos distritos. Com a modificação da métrica do fundo de mapa, damos representatividade espacial à quantidade de pessoas, fator que compõe os fenômenos em questão. Essa alternativa equilibra, por exemplo, o impacto visual entre os distritos com grandes áreas e pouco povoados do extremo sul e os distritos fisicamente menores e com maior população relativa da região leste, apresentando uma espacialidade condizente aos temas investigados.
}

(C) ETD-Educação Temática Digital Campinas, SP v.19 $\quad$ n.esp $\quad$ p. 134-158 jan./mar. 2017 
incialmente, que uma parte considerável das escolas que seriam fechadas são escolas de passagem, definidas como aquelas que não atendem alunos do seu entorno imediato. Muitas vezes, são escolas de referência, procuradas pelos estudantes e seus pais por serem consideradas melhores em infraestrutura e corpo docente.

Nesse sentido, temos que, ao considerarmos a demanda por escola não podemos admitir diretamente o crescimento demográfico negativo de uma região como impactante no número de matrículas escolares. Isso porque podem implicar fatores além da natalidade, da mortalidade e da migração. Dentre os estímulos pela mobilidade diária entre os distritos em busca da melhor escola, outro fator, de natureza distinta, a ser considerado atualmente por conta da crise financeira, é o fluxo de estudantes da escola privada para a pública, gerando um acréscimo na demanda.

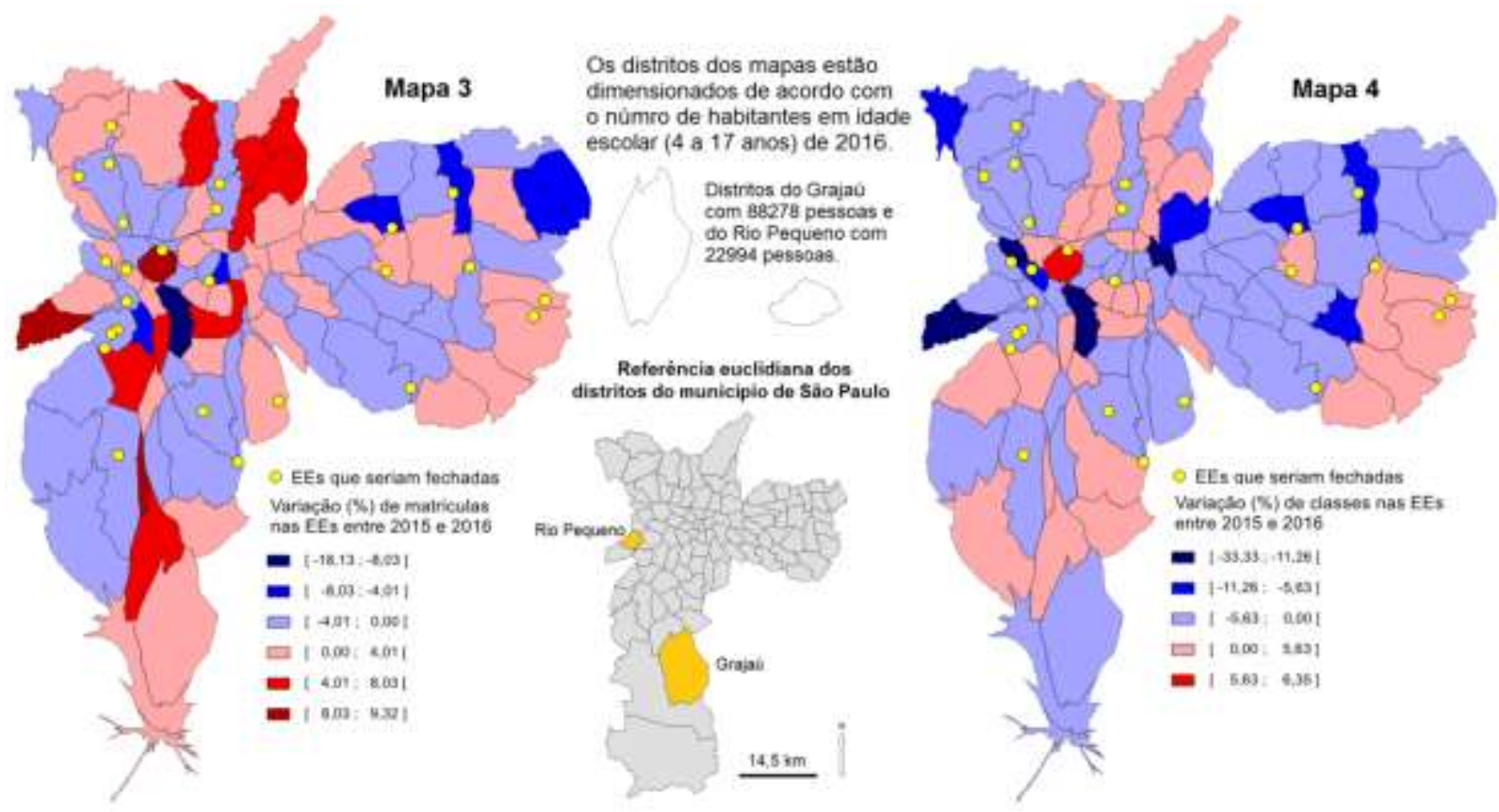

Figura 2 - Comparativo entre a variação de matrículas e de classes nos anos de 2015 e 2016. Mapa 3 - EEs ameaçadas sobre a variação de matrículas. Mapa 4 - EEs ameaçadas sobre a variação de classes.

Fonte: dados de matrícula e de classes obtido pela lei de acesso à informação: SEE-SP. Softwares de elaboração: anamorfose: ScapeToad; discretização: Cartes \& Données. Método estatístico: padrão centrado no zero.

Respeitando essas duas variáveis, como podemos fazer o cálculo de demanda por matrícula de uma região? Ainda que não pretendamos responder a essa questão, passando à análise do mapa 3 , notamos uma confirmação da sua pertinência: mesmo em distritos com decréscimo populacional, verificados nos mapas anteriores, a variação é positiva no número de matrículas. Além de diferenças distritais, é perceptível um contraste mais

(C) ETD-Educação Temática Digital Campinas, SP v.19 n.esp $\quad$ p.134-158 jan./mar. 2017 
generalizado com os mapas anteriores, sobretudo com o azulado mapa 1 , pela leve predominância da mancha vermelha no município no mapa 3. A soma das discrepâncias locais e a nível municipal nos demonstra a insuficiência do argumento que converte automaticamente o decréscimo populacional em variação negativa de matrículas e nos encaminha para a necessidade de apurar quais e como outras variáveis interferem na demanda por escola, trabalho não divulgado pela SEE-SP.

É notório que o fechamento das escolas não ocorreu por conta das ocupações secundaristas, mas apesar do recuo oficial do governador e das dinâmicas multifatoriais que envolvem os movimentos demográficos e de matrícula, podemos observar no mapa 4 que houve redução no número de classes tanto em áreas com crescimento da população entre 4 e 17 anos, quanto naquelas em que houve aumento de matrículas. Quando comparamos os mapas 3 e 4 podemos notar o contraste entre a predominância de tons avermelhados no primeiro e azulados no segundo.

Esse processo pode indicar um provável aumento da relação do número de alunos por sala de aula, e em nenhum momento o documento da SEE-SP discute a problemática do número de alunos por sala de aula, mesmo sabendo que a rede estadual de educação de São Paulo tem uma das maiores relações alunos/classe do país ${ }^{13}$. Tal discussão seria fundamental, uma vez que poderia resultar em uma política de melhora na relação do número de alunos por professores, fator apontado pela literatura científica como um dos elementos com impacto no processo de ensino e aprendizagem.

Contrariamente a uma política de melhoria da relação aluno/classe, no início do ano letivo de 2016, a SEE-SP lançou uma resolução ampliando o número de alunos por classes. Segundo a resolução SE 2, de 09 de janeiro de 2016:

Artigo 2ㅇ - As classes de alunos serão constituídas, de acordo com os recursos físicos disponíveis e na conformidade dos seguintes referenciais numéricos:

I - 30 alunos, para as classes dos anos iniciais do ensino fundamental;

II - 35 alunos, para as classes dos anos/séries finais do ensino fundamental;

III - 40 alunos, para as classes de ensino médio;

IV - 45 alunos, para as turmas de educação de jovens e adultos, nos níveis fundamental e médio.

\footnotetext{
${ }^{13}$ Segundo o indicador educacional "Média de Alunos por Turma", elaborado pelo INEP a partir do Censo Escolar de 2015 para as séries iniciais do ensino fundamental, a rede estadual de São Paulo correspondeu à maior relação alunos/classe do país, com 27,3 alunos por classe. Para as séries finais, foi a maior relação alunos/classe da região Sudeste, com 30,2. Já para o Ensino Médio, a rede ficou em segundo lugar da região Sudeste, com 32,7, perdendo somente para o estado de Minas Gerais, com 33 alunos/classe. Disponível em: http://portal.inep.gov.br/indicadores-educacionais. Acessado em: fev. 2017.
}

(C) ETD-Educação Temática Digital Campinas, SP v.19 n.esp $\quad$ p. 134-158 jan./mar. 2017 
$\S 2$ - - Excepcionalmente, quando a demanda, devidamente justificada, assim o exigir, poderão ser acrescidos até $10 \%$ aos referenciais estabelecidos nos incisos de I ao IV deste artigo. (SEE-SP, 2016).

Na nota técnica de junho de 2016, a Rede Escola Pública e Universidade demonstra o processo de ampliação do número de alunos por sala de aula na rede estadual de São Paulo. Como aponta o documento:

As modas de alunos por classe, de 2015 a 2016, aumentaram em quase todas as etapas e modalidades de ensino. Em 2016, exceto para o Ensino Médio, a moda de alunos por classe é exatamente igual aos referenciais estabelecidos pela Resolução SE n. 02/2016. Particularmente intenso foi o aumento na moda de alunos por classe para a modalidade EJA, que saltou de 36 alunos por classe para 45. Cerca de $14 \%$ das classes estão acima da referência estabelecida pela Resolução SE n. 02/2016. Especialmente preocupante é a situação dos anos iniciais do Ensino Fundamental, que apresentam 24\% das classes com mais alunos que a referência estabelecida. O número de classes acima do limite máximo permitido pela referida Resolução - $10 \%$ a mais do estabelecido - é de $\mathbf{1 , 5 \%}$ das classes. (REDE ESCOLA PÚBLICA UNIVERSIDADE, 2016, p.3, grifos nossos).

Constitui-se, portanto, um movimento de racionalização gerencial dos recursos da rede estadual de educação, com o aumento do número de alunos por sala constituindo-se como estratégia para não aumentar os investimentos diante do crescimento da demanda, conforme aponta o mapeamento realizado. Mesmo com outras características, a realidade atual permanece sendo um processo de reorganização, baseado na lógica central da racionalização dos recursos, discurso que, como vimos, vem acompanhando os documentos sobre o tema desde 1995.

Realizamos trabalho de campo no entorno de uma das escolas que iriam ser fechadas. É notável a área de expansão da fronteira urbana, com aumento populacional e alta vulnerabilidade social, como pode ser verificado nas imagens a seguir:
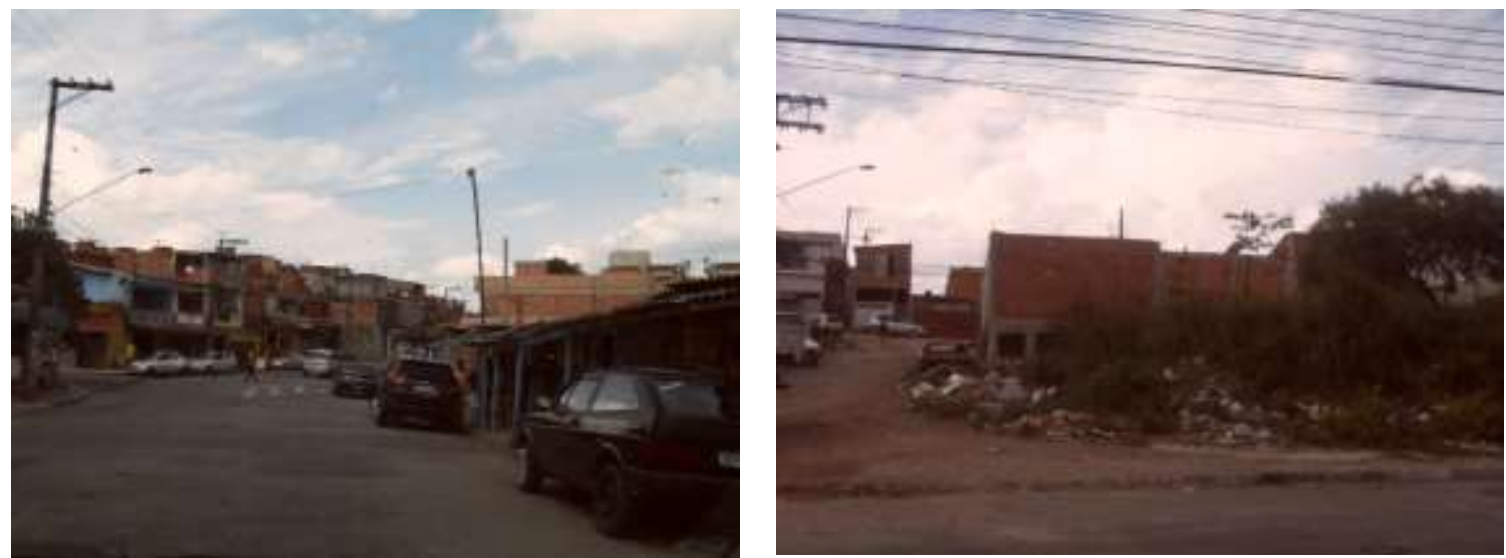

Imagens 1 e 2: Entorno da E. E. Joaquim Suarez, no bairro Fazenda da Juta IV

Fonte: PASSOS, F., outubro de 2016.

(C) ETD-Educação Temática Digital Campinas, SP v.19 n.esp $\quad$ p. 134-158 jan./mar. 2017 
Outro elemento importante a ser analisado é que a proposta de fechamento de unidades escolares e de classes em áreas com aumento de matrícula pode indicar, em nossa perspectiva, a continuidade do processo de municipalização, um dos objetivos da primeira proposta de reorganização analisada por Adrião (2008). Neste novo contexto, sem o diálogo com a prefeitura, como mostram reportagens publicadas pelos principais jornais de São Paulo à época da apresentação da nova proposta de reorganização, a administração municipal tomou conhecimento da reorganização apenas no momento de sua divulgação pública. Este aspecto pode indicar um processo de municipalização velada, uma vez que o fechamento de unidades escolares e classes podem resultar na transferência compulsória de alunos entre as redes. Vejamos o mapa a seguir:

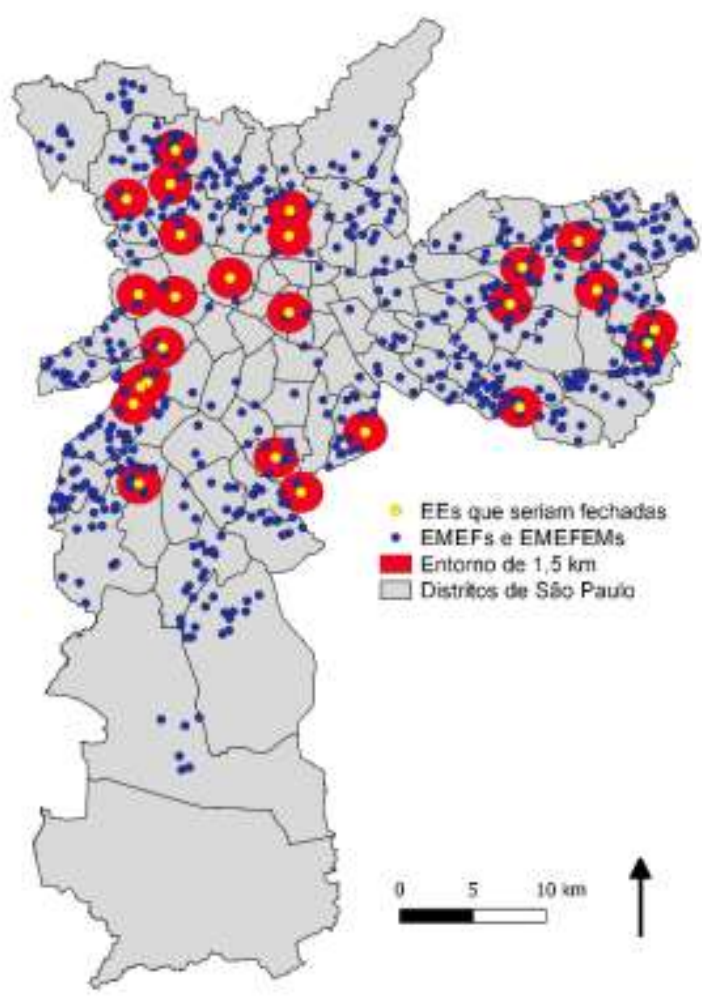

Figura 3 - Mapa 5: Proximidade das EEs ameaçadas em relação às escolas de ensino fundamental e médio da prefeitura de São Paulo.

Fonte: Geosampa, Prefeitura de São Paulo. Software de elaboração: Quantum Gis.

Aplicando a distância de um 1,5 km em relação às unidades escolares - mesma distância definida pela SEE-SP para a realocação dos estudantes entre escolas na proposta da reorganização -, verificamos que há uma grande presença de escolas de Ensino Fundamental sob a administração da prefeitura. Tal concentração é maior em torno das escolas estaduais localizadas na área periférica do que na região central. Neste sentido,

(C) ETD-Educação Temática Digital Campinas, SP v.19 n.esp $\quad$ p. 134-158 jan./mar. 2017 
correlacionando os mapas 2, 3 e 4 encontramos uma situação bastante propícia para um processo de transferência compulsória de alunos da rede estadual para a municipal e que precisa ser investigado com maior detalhe, o que foge do escopo deste artigo.

Na ocasião da apresentação das 93 escolas que seriam fechadas pela reorganização, a SEE-SP divulgou de maneira vaga e evasiva uma lista com os possíveis usos futuros dos respectivos imóveis ${ }^{14}$. Com descrições tais como "vai virar possível ETEC" ou "utilização do Centro Paula Souza ou prefeitura" (grifos nossos), a secretaria demonstram incerteza sobre o destino dos prédios escolares, permitindo questionamentos de quais são os reais objetivos dessas escolas serem desativadas, pois, além da falta de comunicação com as prefeituras, o governo estadual havia aprovado redução de repasses públicos para as ETECs e FATECs ${ }^{15}$. Cabe ressaltar que há pouca transparência em dados oficiais sobre o destino dos lotes das escolas fechadas em 1995.

Desse modo, é fundamental perguntar: por que determinada escola vai fechar? Quais características ela tem que despertam este interesse? Fundamentando o levantamento de hipóteses sobre essa interpelação e lançando mão da linguagem cartográfica na tentativa de responder a tais questões apresentamos os seguintes mapas:

${ }^{14}$ Disponível em: http://g1.globo.com/sao-paulo/noticia/2015/10/veja-lista-das-94-escolas-da-rede-estadualde-sp-que-serao-fechadas.html. Acessado em: nov.2016.

15 “Alckmin investiu R\$ 44 milhões a menos em Etecs e Fatecs", reportagem de Fabio Leite em O Estado de S. Paulo. Disponível em: http://educacao.estadao.com.br/noticias/geral,alckmin-investiu-r-44-mi-a-menos-emetecs-e-fatecs,10000048958. Acessado em: dez.2016.

(C) ETD-Educação Temática Digital Campinas, SP v.19 n.esp $\quad$ p. 134-158 jan./mar. 2017 


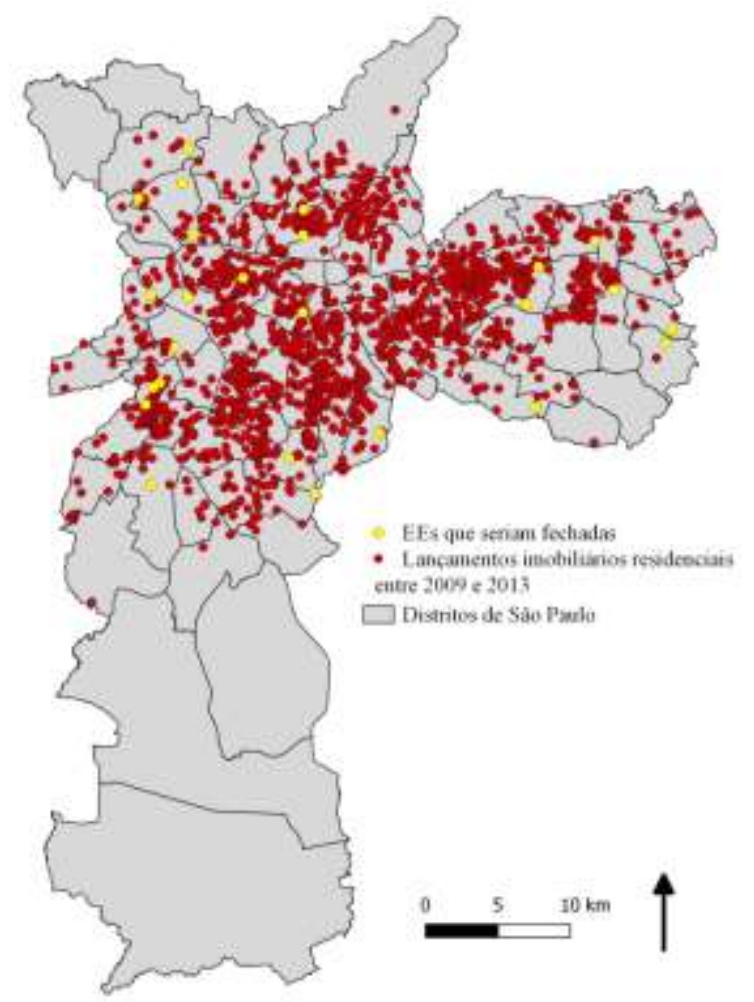

Figura 4 - Mapa 6: EEs ameaçadas sobre lançamentos imobiliários residenciais entre 2009 e 2013.

Fonte: Geosampa, Prefeitura de São Paulo; dados imobiliários: Centro de Estudos da Metrópole.

Software de elaboração: Quantum Gis.

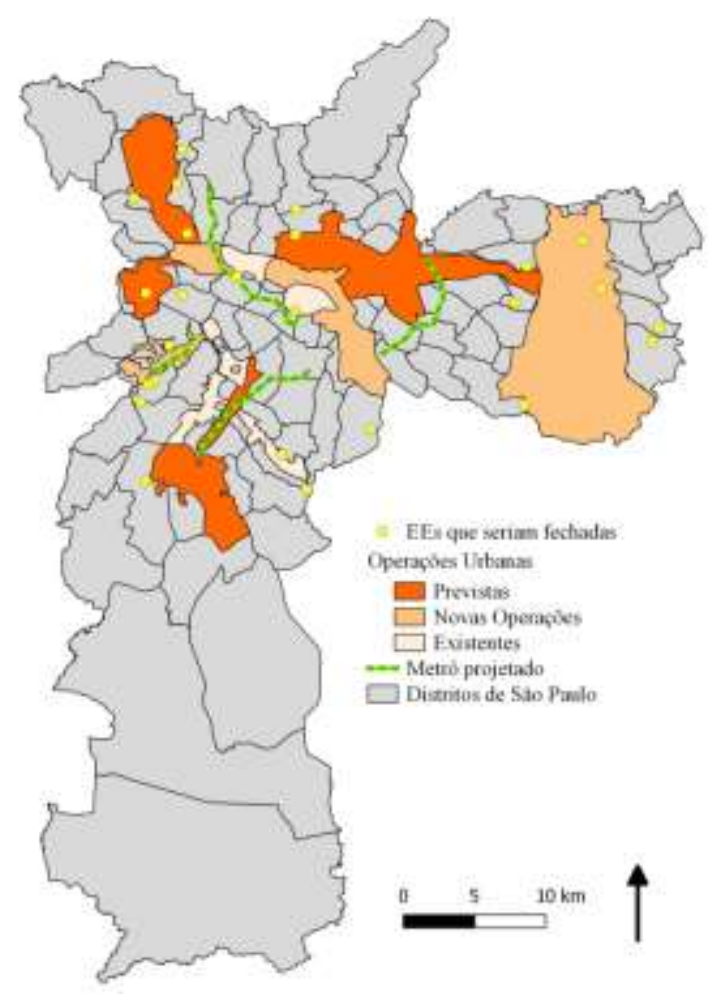

Figura 5 -

Mapa 7: EEs ameaçadas sobre operações urbanas e projeções de linhas de metrô.

Fonte: Geosampa, Prefeitura de São Paulo; dados das operações urbanas: Software de elaboração: Quantum Gis.

O mapa 6 indica uma evidente correlação entre o fechamento de escolas e a localização das maiores áreas de lançamentos imobiliários residenciais no período entre 2009 e 2013. Esta correlação já foi estudada por França (2010) quando em sua tese de doutorado analisou o fechamento de escolas durante a primeira reorganização da rede estadual de educação feita a partir de 1996. Seguindo as discussões traçadas pelo autor e a correlação apresentada nos mapas, realizamos alguns trabalhos de campo no entorno das escolas que estavam na lista de fechamento da atual proposta de reorganização. As imagens a seguir mostram alguns empreendimentos em fase de construção ou de lançamento próximos a escolas na lista no último projeto de reorganização.

C ETD-Educação Temática Digital Campinas, SP v.19 n.esp $\quad$ p.134-158 jan./mar. 2017 

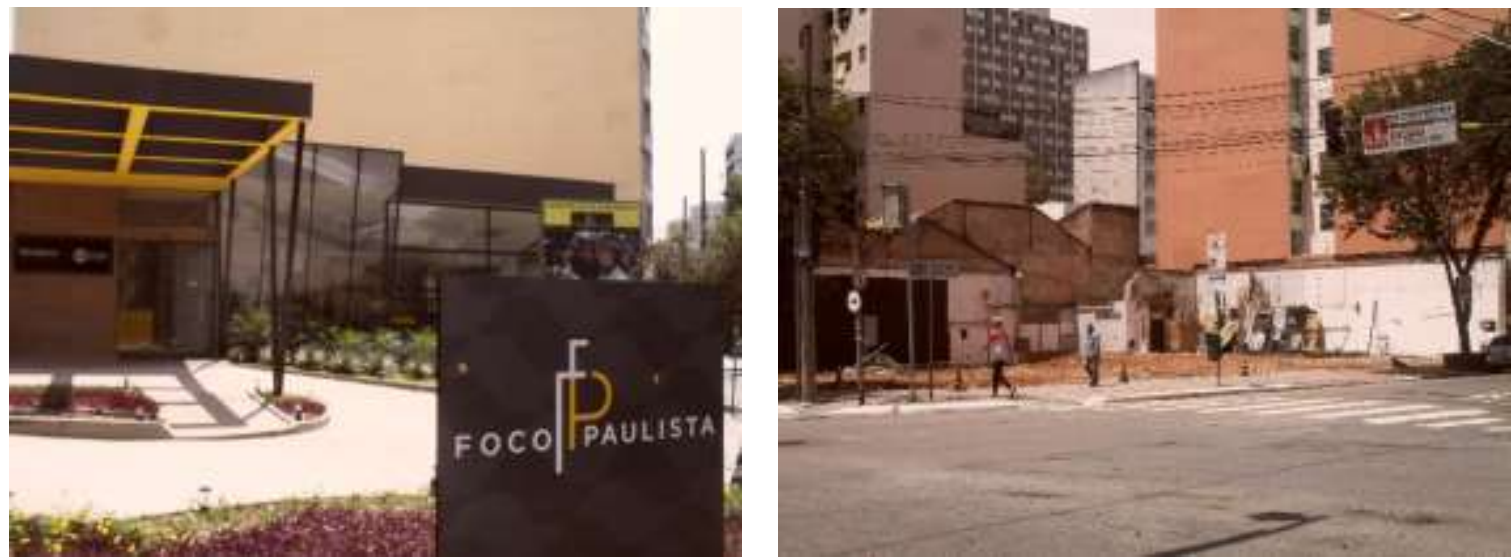

Imagens 3 e 4: Entorno da E. E. Paulo Machado de Carvalho, no bairro da Bela Vista.

Fonte: PASSOS, F., outubro de 2016.
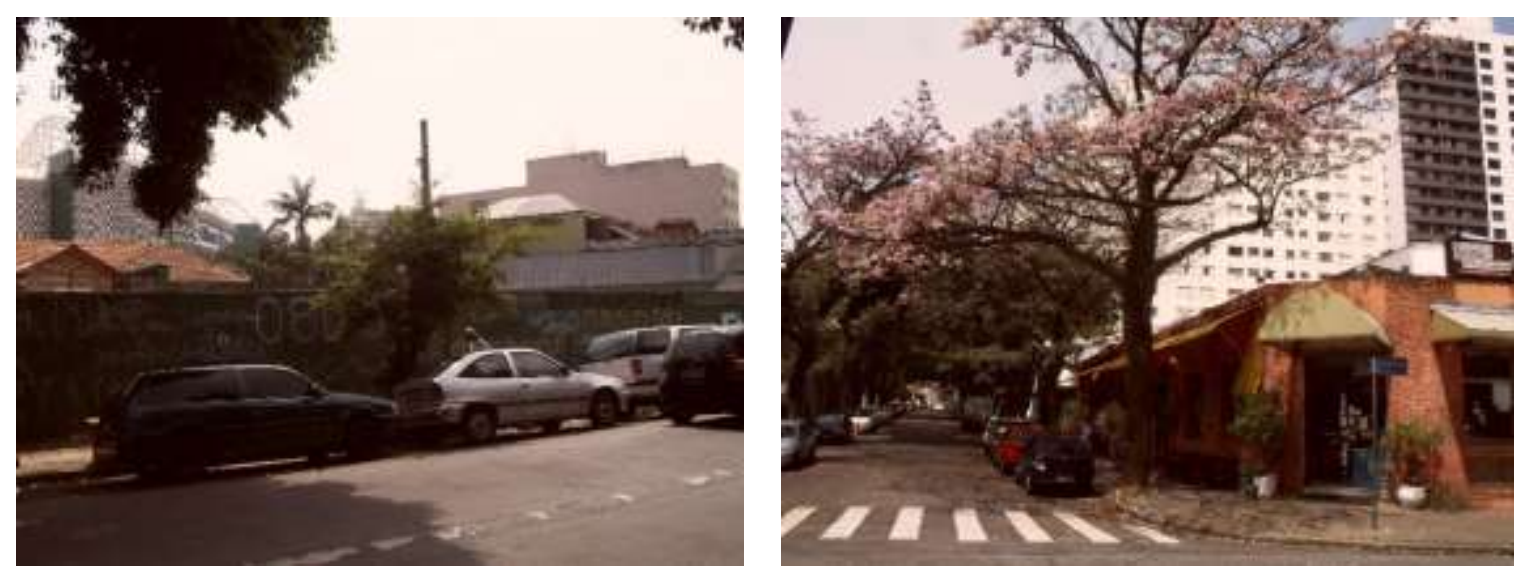

Imagens 5 e 6: Entorno da E. E. Miss Brown, no bairro de Perdizes.

Fonte: PASSOS, F., outubro de 2016.

Nas imagens 3 e 4, vemos um acelerado processo de produção do espaço na região em torno da E.E. Paulo Machado de Carvalho. Trata-se de uma das áreas da região central da cidade de São Paulo que tem passado por um processo substancial de revalorização imobiliária nos últimos anos ${ }^{16}$. Cabe destacar que a E.E. Paulo Machado de Carvalho já atua em ciclo único, o que se contrapõe às justificativas da proposta de reorganização e nos leva a indagar sobre possíveis relações entre o fechamento da unidade escolar e o processo de revalorização urbana no entorno da escola.

\footnotetext{
${ }^{16}$ Entre 2009 e 2013 a Bela Vista teve 39 lançamentos imobiliários, correspondendo ao maior bairro da subprefeitura da Sé, de acordo com os dados tratados pelo Centro de Estudos da Metrópole. Disponível em: http://www.fflch.usp.br/centrodametropole/716. Acessado em: fev. 2017.
}

(C) ETD- Educação Temática Digital Campinas, SP v.19 n.esp p. 134-158 jan./mar. 2017 
As imagens 5 e 6 mostram uma área densamente urbanizada que passa por um processo de valorização intensificada pela construção de uma arena para shows e jogos de futebol, como pode ser verificado na imagem 5. Neste sentido, em ambos os casos analisados verificamos possíveis relações entre o fechamento de unidades escolares e o avanço de processo de valorização do espaço urbano na cidade de São Paulo, reforçando a necessidade de ampliar o entendimento desta relação já iniciada por França (2010).

Um dos processos responsáveis pela revalorização no espaço urbano diz respeito às obras de transporte e de mobilidade urbana. Se observarmos o mapa 6 das Operações Urbanas Consorciadase das escolas que seriam fechadas, é possível estabelecer a correlação espacial desses fatores, concretizados no mapa com lançamentos imobiliários residenciais ${ }^{17}$. No caso das operações urbanas, ressaltamos a forte presença de atores privados materializados por consórcios - reforçando a lógica gerencial de mercantilização da cidade na qual elas são concebidas.

Neste contexto, é possível inferir que o fechamento de escolas, se realizado, participaria de um processo contínuo de ressignificação da cidade, objetivando gerar "um novo espaço", para um outro público, capaz de assumir uma nova função. Cabe sinalizar que "os espaços, assim requalificados, atendem sobretudo a interesses dos atores hegemônicos da economia e da sociedade" (SANTOS, 2008, p. 48). Neste contexto, geram-se tensões relacionadas ao direito à educação eao direito à cidade cujo movimento de ocupações de escolas seria a expressão máxima.

Segundo Henri Lefebvre (2008), o direito à cidade é compreendido como a possibilidade de os sujeitos acessarem e se apropriarem da cidade, fazendo dela uma obra coletiva, desatrelada dos imperativos do mercado e da lógica do lucro:

O direito à cidade não pode ser concebido como um simples direito de visita ou de retorno às cidades tradicionais. Só pode ser formulado como direito à vida urbana, transformada, renovada. [...] lugar de encontro, prioridade do valor de uso, inscrição no espaço de um tempo promovido à posição de supremo bem entre os bens, encontre sua base morfológica, sua realização prático-sensível. (LEFEBVRE, 2008, p. 117-118).

É importante ressaltar, como aponta Harvey (2014), que o direito à cidade vem sendo exercido de forma privilegiada por grupos que se apropriam dos instrumentos e mecanismos de produção do espaço urbano, dando-lhe as formas e conteúdos que

\footnotetext{
${ }^{17}$ Operação Urbana Consorciada é um instrumento de planejamento urbano previsto pelo Estatuto das Cidades (Lei no 10.257 de 2001) que tem por finalidade promover transformações urbanísticas estruturais, melhorias sociais e valorização ambiental em determinado setor da cidade. É coordenado pelo poder público em parceria com proprietários, investidores privados, usuários e moradores permanentes.
}

(C) ETD-Educação Temática Digital Campinas, SP v.19 n.esp $\quad$ p. 134-158 jan./mar. 2017 
reproduzem os seus interesses. Ao decidirem como a cidade deve ser, tais grupos, vinculados ao setor imobiliário-financeiro, delimitam os usos, as formas e os padrões de apropriação que, na maioria dos casos, têm como mediação o dinheiro, ressaltando assim o uso privado da cidade.

Neste sentido, na perspectiva defendida por Harvey, o direito à cidade é sempre um direito em disputa e que coloca em movimento e discussão qual projeto de sociedade se busca construir. Desse modo, as ações dos estudantes de ocuparem suas escolas ultrapassou a defesa exclusiva do ambiente escolar, perceptível através da valorização dos encontros e da livre apropriação da escola. Mesmo que necessite de maiores investigações sobre as intenções desses estudantes, é possível inferir que o movimento de ocupações correspondeu a uma resistência ao processo de valorização espacial apontado pela última proposta de reorganização e demonstrado aqui nos mapas 6 e 7. 0 que denota dizer que as ações de ocupar escolas públicas representaram, mesmo que em gérmen, o interseccionamento da defesa da educação pública pelo direito à cidade.

\section{CONSIDERAÇÕES}

Apresentamos neste artigo os resultados parciais do projeto A reorganização em Mapas, iniciado em julho de 2016. Cada tema dos mapas realizados representa uma frente de trabalho de investigação que precisa ser ampliada e aprofundada. Entre as principais dificuldades encontradas até o momento está a falta de acesso aos dados oficiais da rede estadual de educação de São Paulo, o que impossibilita um diagnóstico mais preciso dos fenômenos analisados.

No entanto, pensamos ser fundamental partilhar estes primeiros resultados, mesmo que parciais, com a comunidade acadêmica e a sociedade civil, pois, em nossa perspectiva, é essencial que a dimensão espacial das políticas públicas seja reconhecida, problematiza e discutida. Trata-se do entendimento de que as políticas educacionais postas em prática nas últimas décadas no estado de São Paulo têm em sua lógica constitutiva uma espacialidade, mesmo que não explicitada nos documentos oficiais. Trazer à tona e compreender esta lógica é processo fundamental para que possamos construir alternativas a esse modelo de educação combinado a precarização, no aprofundamento das desigualdades educacionais e socioespaciais, seus principais parâmetros.

E se nos serve de alento, os estudantes secundaristas já entenderam a força da dimensão espacial dos fenômenos: se a reorganização escolar propunha uma política espacial autoritária e homogênea, com as lutas nas ocupações, eles produziram outra

(C) ETD-Educação Temática Digital Campinas, SP v.19 n.esp $\quad$ p. 134-158 jan./mar. 2017 
geografia da escola pública, mais diversa e horizontal, que nos aponta caminhos para a construção de outra escola e, no limite, de outra sociedade.

\section{REFERÊNCIAS}

ADRIÃO, Theresa. Educação e produtividade: a reforma do ensino paulista e a desobrigação do Estado. São Paulo: Xamã, 2006.

ADRIÃO, Theresa. Oferta do Ensino Fundamental em São Paulo: um novo modelo. Educação e Sociedade, Campinas, SP, v. 29, n. 102, jan./abr., 2008.

CASTRO, Maria Helena Guimarães de. Educação para o século XXI: o desafio da qualidade e da equidade. Brasília: INEP, 1999.

FRANCA, Gilberto Cunha. Urbanização e educação: da escola de bairro à escola de passagem. 2010. Tese (Doutorado em Geografia Humana). FFLCH, USP. São Paulo.

HARVEY, David. A produção capitalista do espaço. São Paulo: Annablume, 2005.

HARVEY, David. Cidades rebeldes. São Paulo: Martins Fontes, 2014.

KANE, Thomas; GORDON, Robert; STAIGER, Douglas. Identifying efective teachers using perfomance on the job.The BrookingsInstitution, 2006.

LEFBVRE, Henri. Direito à cidade. São Paulo: Centauro, 2008.

NEUBAUER, Rose; SILVEIRA, Ghislaine Trigo. Gestão dos sistemas escolares: quais caminhos perseguir? São Paulo: IFHC, 2008.

PANTOJO, Bruno; SALOMÃO, Laudina de Andrade; CASTRO, Maria Nícia Pestana de; MARTINS, Marcelo. Escolas estaduais com uma única etapa de atendimento e seus reflexos no desempenho dos alunos. São Paulo: CIMA-SEE-SP, 2015.

REDE ESCOLA PÚBLICA UNIVERSIDADE. Análise da resposta da Secretaria da Educação do Estado de São Paulo (Departamento de Planejamento e Gestão da Rede Escolar e Matrícula - DGREM) à Ação Civil Pública (ACP) movida pelo Ministério Público do Estado de São Paulo e Defensoria Pública do Estado de São Paulo, processo n. 104968305.2015.8.26.0053. São Paulo, 2016. Disponível em: http://www.observatoriodaeducacao.org.br/images/pdfs/nota.tecnica.\%20reorganizacao.2 016.pdf. Acessado em: nov. 2016.

SANTOS, Milton. Técnica, espaço, tempo: globalização e meio técnico-científicoinformacional. São Paulo: Editora da Universidade de São Paulo, 2008.

(C) ETD-Educação Temática Digital Campinas, SP v.19 n.esp $\quad$ p. 134-158 jan./mar. 2017 
SÃO PAULO (Estado). Mudar para melhor: uma escola para criança e outra para o adolescente - reorganização das escolas da rede estadual. São Paulo: SEE, 1995.

SÃO PAULO (Estado). Censo escolar do estado de São Paulo. São Paulo: SEE, 2014.

SÃO PAULO (Estado). Resolução SE 2. São Paulo: SEE, 2016. Disponível em:

http://siau.edunet.sp.gov.br/ItemLise/arquivos/2 16.HTM?Time=24/02/2017\%2018:06:14.

Acessado em: fev. 2017.

SASS, Odair.; MINHOTO, Maria Angélica. Indicadores e educação no Brasil: a avaliação como tecnologia. In: Constelaciones. Revista de Teoria Crítica. № 2, dezembro de 2010.

'Revisão gramatical do texto: Eveline A. da Silva. Email: evelinealmeidadasilva@gmail.com

(C) ETD-Educação Temática Digital Campinas, SP v.19 n.esp $\quad$ p. 134-158 jan./mar. 2017 